\title{
Identification of Two Novel Regulatory Elements in the IL2RA Gene Locus
}

Rosa $F^{1,2}$, Rameil $\mathbf{P}^{3,4}$, Algarté-Génin $\mathbf{M}^{5}$, Bedotto $\mathbf{M}^{1,2}$, Ferrier $\mathrm{P}^{6,7}$, Cauchy $\mathbf{P}^{1,2,6,7,8^{*}}$ and $\operatorname{Imbert} \mathbf{J}^{1,2^{\star}}$

1 University of the Mediterranean, Marseille, France

2INSERM- National Institute of Health and Medical Research, U1090, TAGC, Marseille, France

3INSERM- National Institute of Health and Medical Research, UMR1068, CRCM, Marseille, France

${ }^{4}$ CNRS- National Center for Scientific Research, UMR7258, CRCM, Marseille, France

5 INSERM- National Institute of Health and Medical Research, U943, Paris, France

${ }^{6}$ CNRS- National Centre for Scientific Research, UMR7280, CIML, Marseille, France

'INSERM- National Institute of Health and Medical Research, U1104, CIML, Marseille, France

${ }^{8}$ Max Planck Institute for Immunobiology and Epigenetics, Freiburg, Germany

\begin{abstract}
Regulatory T-cells $\left(T_{\text {regs }}\right.$ ) express the high-affinity chain of the interleukin 2 (IL-2) receptor, CD25, encoded by the IL2RA gene. IL2RA is one of the most extensively characterized genes regarding its regulatory regions and their functional links to cell surface receptors and their associated signal transduction cascade in the context of the antigen-dependent activation of mature $\mathrm{CD} 4^{+} \mathrm{T}$ lymphocyte. However, converging evidences strongly suggested that they were some missing pieces in this already complex puzzle made of 6 well-characterized regulatory regions. Here, by combining principally in silico genomic footprinting approach and meta-analysis of several ChIP-seq studies, we identified and characterized 2 new putative CD28-responsive elements. We show that a recently-characterized intronic enhancer at $+11 \mathrm{~kb}$ harbors a functional CREB site. Further, we evidence a repressor element consisting of two GAAA repeats located 5'-most of a previously identified enhancer $4 \mathrm{~kb}$ upstream of the IL2RA gene. Massspectrometry analyses revealed Poly ADP-ribose polymerase 1 (PARP-1) as part of the complexes binding this element. Altogether, our observations extend our understanding of the molecular basis of the multiple options offered by such a complex organization in term of $\mathrm{T}$ cell responses.
\end{abstract}

Keywords: IL2RA; Enhancer; Regulatory T-cell; Gene regulation; CREB; PARP-1; EMSA

\section{Introduction}

Regulatory T-cells $\left(\mathrm{T}_{\text {regs }}\right)$ are immunosuppressive $\mathrm{CD} 4^{+} \mathrm{T}$-cells that constitutively express the high-affinity chain of the interleukin 2 (IL-2) receptor, CD25, and the forkhead P3 (FoxP3) transcription factor (TF) [1,2]. Like other helper T-cells $\left(\mathrm{Th}_{1}, \mathrm{Th}_{2}, \mathrm{Th}_{17}\right)$, these cells are thought to originate from T-cells activated by antigen presentation, during which T-cell receptor (TCR), CD3 stimulation and CD28 co-stimulation take place [3]. Conversely, in other inactive helper T-cells, CD25 expression is downregulated, which makes CD25 a specific marker for $\mathrm{T}_{\text {regs }} \mathrm{T}_{\text {reg }}$ ontogeny is specifically promoted by tumor growth factor $\beta$ (TGF $\beta$ ) in an autocrine and paracrine manner [4]. TGF $\beta$ and interleukin 10 (IL10) secretion confers $T_{\text {regs }}$ a prominent role in suppressing autoreactive T-cells and in regulating cell- and humoral-mediated immune responses $[4,5]$. Due to their immunosuppressive nature, these cells also largely play a role in suppressing allergy and asthma [6,7]. The maintenance of $\mathrm{T}_{\text {reg }}$ populations is thus critical to suppress allergenic $\mathrm{Th}_{2}$ cells via IL-10 and TGF $\beta$ secretion $[8,9]$. However, in autoimmune diseases and severe allergic pathologies, the ratio of $\mathrm{Th}_{2} / \mathrm{T}_{\text {regs }}$ cells tend to be biased towards Th2 cells, resulting in reduced immunosuppression [10-12]. In some cases of allergy, this discrepancy even seems to originate neonatally [13].

CD25 is encoded by the IL2RA gene and is one of the three subunits of the IL-2 receptor, which constitutes the centerpiece of the IL-2/IL-2R system [14]. The low affinity IL-2 receptor comprises the constitutivelyexpressed $\beta$ and $\gamma$ chains only. The $\beta$ chain is shared with the receptor for IL-15, while the $\gamma$ chain is shared with that of IL-4, IL-7, IL-9, IL15 and IL-21 [15]. The IL-2 receptor acts synergistically with TCR and CD28 (co)-stimulation to induce cell survival and proliferation in T lymphocytes [16]. CD25 is normally expressed in DN2/3 thymocytes [17], basophils [18], activated T-cells [19] and marginally in circulating B-cells [20]. IL-2 binding to the medium-affinity IL-2 receptor triggers oligomerization of the $\beta$ and $\gamma$ chains, which initiates transduction of three signaling pathways: (i) JAK-STAT [21], (ii) MAP-kinase [22] and (iii) PI3-kinase [23], thereby inducing the expression of early-response genes, including $I L-2$ itself and IL2RA. This results in an amplification of high affinity IL-2 receptors at the cell surface. Due to these properties, CD25 is a therapeutic monoclonal antibody target [24]. In fact, inactivation of the high-affinity murine IL-2 receptor causes loss of $\mathrm{T}_{\text {regs }}$ and subsequent invasive auto-immune inflammation of the intestine [25]. In humans, a truncated form of CD25 was associated with reduced peripheral T-Cell count and proliferation but normal B-cell development [26]. CD25 expression is also higher in allergenspecific T-cell clones in cow's milk allergy [27].

Transcriptional regulation of IL2RA is a tightly-regulated process that requires activation of the full complement of its cognate pathways for optimal expression. Due to its critical role in immunity, IL2RA represents one of models of gene regulation as one of the bestcharacterized loci to date. Six pathway-specific responsive enhancers or positive regulatory regions (PRRs) have been described: PRRI/II/V/ VI are required for initial antigenic and mitogenic stimulation [26,2830], while PRRIII/IV are subsequently activated by IL-2 via JAK-STAT [31-34]. Combinatorial activation of these enhancers is achieved via binding of transcription factors (TFs) responding to specific signaling

${ }^{*}$ Corresponding author: Jean Imbert, INSERM- National Institute of Health and Medical Research, U1090, TAGC, Marseille, France, Tel: (+33)(0)491828703, Fax: (+33)(0)491828700; E-mail: jean.imbert@inserm.fr

Pierre Cauchy, Max Planck Institute for Immunobiology and Epigenetics, Freiburg, Germany, Tel: (+49) (0)7615108730, Fax: (+49)(0)7615108220; E-mail: cauchy@ie-freiburg.mpg.de

Received April 30, 2018; Accepted May 03, 2018; Published May 09, 2018

Citation: Rosa F, Rameil P, Algarte-Genin M, Bedotto M, Ferrier P, et al. (2018) Identification of Two Novel Regulatory Elements in the IL2RA Gene Locus. J Pulm Respir Med 8: 458. doi: 10.4172/2161-105X.10004587

Copyright: ( 2018 Rosa F, et al. This is an open-access article distributed under the terms of the Creative Commons Attribution License, which permits unrestricted use, distribution, and reproduction in any medium, provided the original author and source are credited. 
pathways. Thus, PRRI/II possess ETS and NF- $\kappa B$ binding sites, and PRRIII/IV STAT binding sites [14]. Importantly, PRRV and VI are CD28-responsive elements due to the presence of CREB binding sites in these enhancers $[26,30]$. Consistent with $\mathrm{T}_{\text {reg }}$ ontogeny, PRRV also harbors a TGF $\beta$ response element (SMAD) that favors TCR engagement and promotes $\mathrm{T}_{\text {reg }}$ differentiation [14].

The IL2RA locus also bears further large conserved non-coding sequences (CNS) in the human and mouse IL2RA locus identified via phylogenetic footprinting $[14,35,36]$, suggesting additional, unidentified regulatory elements. In fact, two additional putative enhancer sites were characterized as demethylated regions using MeDIP-chip [37]. These enhancers are located $\sim-8 \mathrm{~kb}$ upstream of the TSS and $\sim+25 \mathrm{kbp}$ in the first intron of IL2RA. More recently, further regulatory elements were identified via CRISPR-activation (CRISPRa) screening in the $I L 2 R A$ locus in a landmark study, also allowing a direct comparison of enhancer activities of previously published enhancers in this locus [38]. This work was largely supported by the recent rise of high-throughput techniques, both for sequencing of transduced gRNA libraries as well as upstream target identification using published ENCODE ChIP-Seq and DNaseI-Seq screens [39]. This work uncovered two new regions in the first intron of $I L 2 R A$, located at $\sim+9 \mathrm{~kb}$ and $\sim+11 \mathrm{~kb}$ into the first intron. The element at $\sim+9 \mathrm{~kb}$, called CasRE4, was validated as an enhancer via SNP and indel knock-in assays. Using targeted deletion via CRISPR, both elements (designated IN1a and IN1b) and an additional enhancer at $\sim-27 \mathrm{~kb}$ (UP1) were also validated in a subsequent study as STAT5-dependent as well as required for correct CD25 expression [40]. Altogether, although these studies evidenced novel functional regulatory elements in the IL2RA locus, they also call for further characterization of single binding sites within enhancers in this locus.

A 12 base-pair (bp) element upstream of PRRIII IL-2rE was previously identified via genomic footprinting as subject to constitutive and inducible modifications of the chromatin in Kit 225 cells [41]. Furthermore, antigen-mimicking $\alpha \mathrm{CD} 2 / \alpha \mathrm{CD} 28$ activation of primary T-Cells caused transitory migration delays of a protein complex located in PRRIII via band-shift assays [33].

In this study, we identify putative CREB, ETS and STAT binding sites via phylogenetic footprinting in the CasR4/IN1b element, which we designated PRRIX. We validate the presence of a complex specifically binding the novel CREB binding site. Further, we evidence a novel binding site at the 5' extremity of PRRIII. We highlight the repressive nature of this element with regards to gene expression. Finally, we identify one of the components of the protein complex binding to the GAAA element as Poly ADP-ribose polymerase 1 (PARP-1) enzyme.

\section{Materials and Methods}

\section{Cell culture and cell extracts}

Kit 225 cells were cultured in 10\% FCS RPMI 1640 medium with $2 \mathrm{~mm}$ l-glutamine, $100 \mu \mathrm{g} / \mathrm{ml}$ each of streptomycin and penicillin, and $10 \%$ fetal bovine serum at $37^{\circ} \mathrm{C}$ with $5 \% \mathrm{CO}_{2}$ and split every other day. When performed, IL-2 stimulation was carried out for $1 \mathrm{~h}$ prior to cell lysis as described [41]. Cells were harvested at a density of $8 \times 105$ cells/ $\mathrm{ml}$, and nuclear extracts were prepared as described previously [41]. Nuclear extracts were then subjected to an ammonium sulfate cut $(0.33$ $\mathrm{g} / \mathrm{ml}$ extract) and pelleted by centrifugation as described previously (7). The resulting extract was then dissolved in TM buffer $(50 \mathrm{~mm}$ Tris-

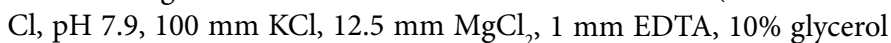
$(\mathrm{v} / \mathrm{v}))$.

\section{Electrophoretic mobility shift assays (EMSAs)}

Probes were designed using the sequences of analyzed regions. For $\mathrm{GAAA}_{\mathrm{wt}}$, we used the oligonucleotide sequence CTAGAAAGAAAGTGGTCTTAA. For $\mathrm{IX}_{\mathrm{wt}}$ the oligonucleotide sequence GAGTTAAAGTTGACGTCAGCCTCTTCCT GCCCTGGTGCCCCGAGAGTTTCCCGGGAGTTTTGG was used. Double-stranded oligonucleotide probes were were end labeled with $\left[\gamma^{-32} \mathrm{P}\right]$ ATP. Competitors were not labeled and their sequences were as follows CTAGAAAGAAATGTTTCTTAA $\left(\right.$ GAAA $\left._{\text {mul }}\right)$, CTACCAACCAAGTGGTCTTAA $\left(\right.$ GAAA $\left._{\text {mu23 }}\right)$ and CTACCAACCAATGTTTCTTAA (GAAA ${ }_{\text {mu123 }}$ ). The FcgRI-GAS [33] competitorsequencewasGTATTTCCCAGAAAAGGAAC; thesequence for the EBSa competitor [33] was GATAAACAGGAAGTGGTTGTA and the sequence of high-affinity CREa competitor [42] was CGCCTTGAATGACGTCAAGGC. Nuclear extracts $(300 \mu \mathrm{g})$, probes and 25,50, 75 and 100X excess competitors were migrated for $1 \mathrm{~h}$ at $110 \mathrm{~V}$ using $2.5 \%$ sodium dodecylsulfate polyacrylamide gel electrophoresis (SDS-PAGE).

\section{In vivo dimethyl sulfate/ligation-mediated PCR (DMS/LM- PCR) genomic footprinting}

DMS/LM-PCR genomic footprint analyses were performed as described in [41]. Primer sequences and associated melting temperatures can be found in Table 1 .

\section{Gene reporter assays}

Kit 225 cells were co-transfected with $0.8 \mu \mathrm{g}$ GAAA $_{w t}$ (CTAGAAAGAAAGTGGTCTTAA) and $\kappa$ B-luciferase plasmid. Cells were grown to $80 \%$ confluent in 6 well plates and were transfected on the following day by Lipofectamine ${ }^{\mathrm{TM}} 2000$ (LF2000; Invitrogen). DNA and LF2000 were premixed for $20 \mathrm{~min}$ and then applied to the cells. After $24 \mathrm{~h}$ transfection, the cells were then incubated with the indicated agents. After further $24 \mathrm{~h}$ incubation, the media were removed, and cells were washed once with cold PBS. To prepare lysates, $100 \mu \mathrm{l}$ reporter lysis buffer (Promega, France) was added to each well, and cells were scraped from dishes. The supernatant was collected after centrifugation at $13,000 \mathrm{rpm}$ for $2 \mathrm{~min}$. Aliquots of cell lysates $(20 \mu \mathrm{l})$ containing equal amounts of protein $(20$ to $30 \mu \mathrm{g})$ were placed into wells of an opaque black 96-well microplate. An equal volume of luciferase substrate was added to all samples, and luminescence was measured in a microplate luminometer.

\section{DNA affinity purification assay (DAPA)}

Nuclear extracts were incubated with ${ }^{32} \mathrm{P}$-radioactively labeled GASd sequence (5'-TTTCTTCTAGGAAGTACC-3'), GAAA (5'- CTACCAACCAAGTGGTCTTAA-3') and GAAA $_{\mathrm{wt}}$ sequence (5'-CTAGAAAGAAAGTGGTCTTAA-3'). Binding of complexes was assayed, as described [43]. Following $0 \mathrm{~h}, 1 \mathrm{~h}$ and $24 \mathrm{~h}$ exposures with IL-2, nuclear extracts were separated using SDS PAGE and subsequently

\begin{tabular}{|c|l|c|}
\hline Primers & Sequences & $\mathrm{Tm}$ \\
\hline 1 & -4032 CCCCTCTCTACTTCTGGTT -4014 & $60^{\circ} \mathrm{C}$ \\
\hline 2 & -4000 ACTCTGCTTCCTCAGGAACCACCTA -3976 & $63^{\circ} \mathrm{C}$ \\
\hline 3 & -3990 CTCAGGAACCACCTACCAAGGCCGTATCCATCC - & $70^{\circ} \mathrm{C}$ \\
\hline 4 & 3958 & $60^{\circ} \mathrm{C}$ \\
\hline 5 & -3651 CAAGGAAAGAACTTGAACAAGG - 3630 & $63^{\circ} \mathrm{C}$ \\
\hline 6 & -3703 GAACGTGACAACTGGCCGACAGGACCTAC -3675 & $68^{\circ} \mathrm{C}$ \\
\hline
\end{tabular}

Table 1: Nucleotide sequences, localizations and melting temperatures of each primer set for DMS/LM-PCR genomic footprint analyses. 
Citation: Rosa F, Rameil P, Algarte-Genin M, Bedotto M, Ferrier P, et al. (2018) Identification of Two Novel Regulatory Elements in the IL2RA Gene Locus. J Pulm Respir Med 8: 458. doi: 10.4172/2161-105X.1000458

revealed using silver nitrate staining. Bands of interest were cut, purified via high-performance liquid chromatography (HPLC) and sequenced using mass spectrometry.

\section{Phylogenetic footprinting}

Phylogenetic footprinting was performed via ECR browser at dCode [44]. To map conserved motifs, we used the multiTF conserved motif searching facility at dCode, using Homo sapiens, Pan troglodytes, Macaca mulatta, Mus mus musculus, Rattus norvegicus and Canis familiaris to retrieve synteny blocks. MultiZ alignments were derived from the UCSC genome browser [45]. Phylogenetic analyses of enhancer regions were carried out via ClustalX using bootstrapping [46].

\section{Results}

\section{PRRIX (CasRE4/IN1b) contains a functional CRE-binding element}

PRRIX (CasRE4) was recently identified as functional enhancer essential for physiological CD25 expression, containing at least one characterized STAT5 binding site $[38,40]$. Inspection of the IL2RA locus using publicly available T-cell ENCODE DNAseI-Seq datasets
[39] revealed open chromatin at this enhancer and the neighboring one at $+9 \mathrm{~kb}$ (CasRE4/IN1a which we designated PRRVIII), as well as at previously described ones, PRRI, II, III and IV (Figure 1A). Interestingly, PRRIX displayed open chromatin in all types of T-cells, including $\mathrm{Th}_{0}$, as well as in B-cells. The regions characterized at $-8 \mathrm{~kb}$ and $+25 \mathrm{~kb}$ identified by Schmidl et al [37], which we called PRRVII and PRRIX, also showed enrichment in open chromatin. To further characterize potential novel binding sites in PRRIX, we performed phylogenetic footprinting combined with motif discovery in the entire IL2RA locus. Immunity-related genes tending to evolve more quickly than others, we chose closely related mammals as comparison species [10]. We identified seven conserved, motif-rich, regions in the IL2RA (Figures 1A and S1). In PRRIX, we found CREB, ETS and STAT motifs conserved in most of the selected mammal species (Figure 1B). Inspection of PRRIII also revealed the presence of a unknown motif at the 5 ' end (between -3842 bp and -3831 bp from the TSS) conserved in higher primates, which we called GAAA in reference to its sequence GAAAGAAAGTGG (Figure 1B). PRRX was also characterized by the presence of a RUNX motif. By performing further phylogenetic footprinting, while we observed that PRRIX was well conserved, this was not the case for PRRVI, one of the known CD28-responsive elements (CD28-rE) in IL2RA, was not well conserved (Figures S2A

A

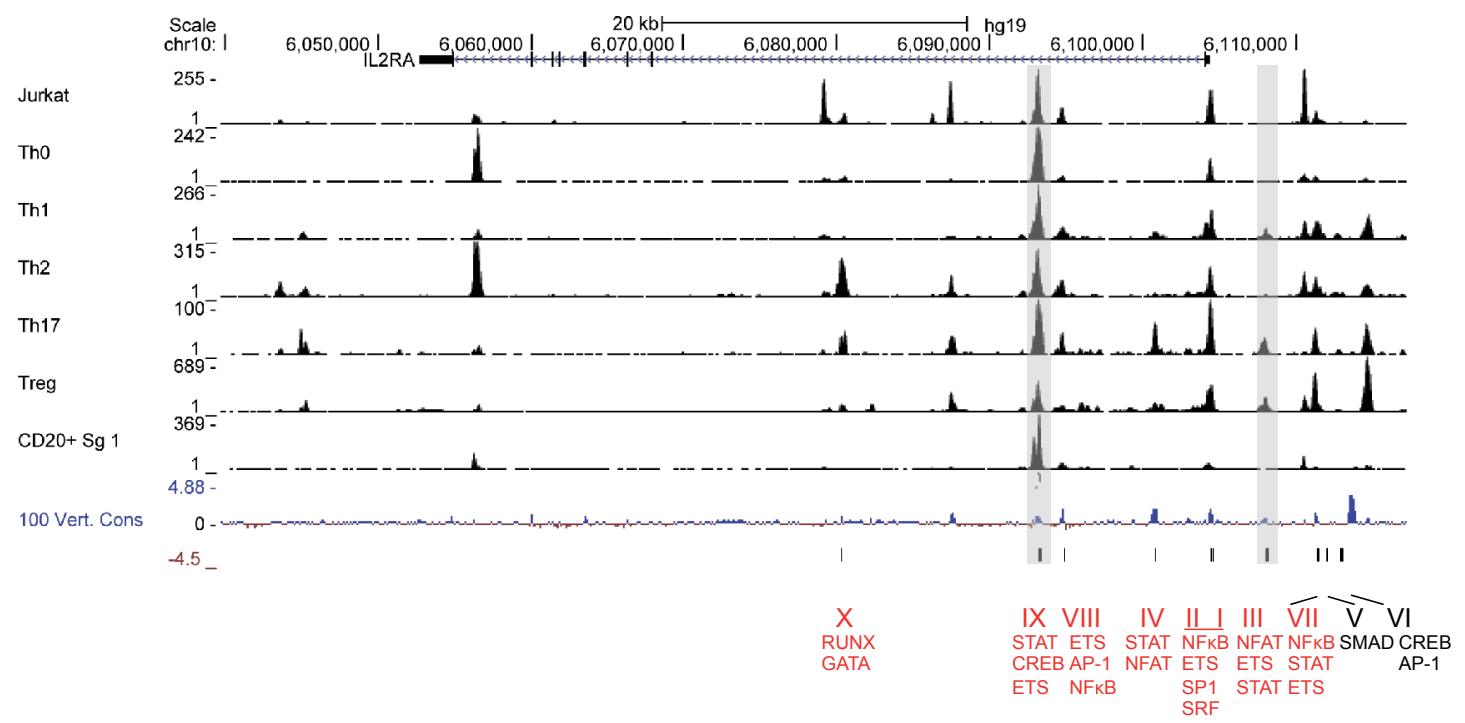

B

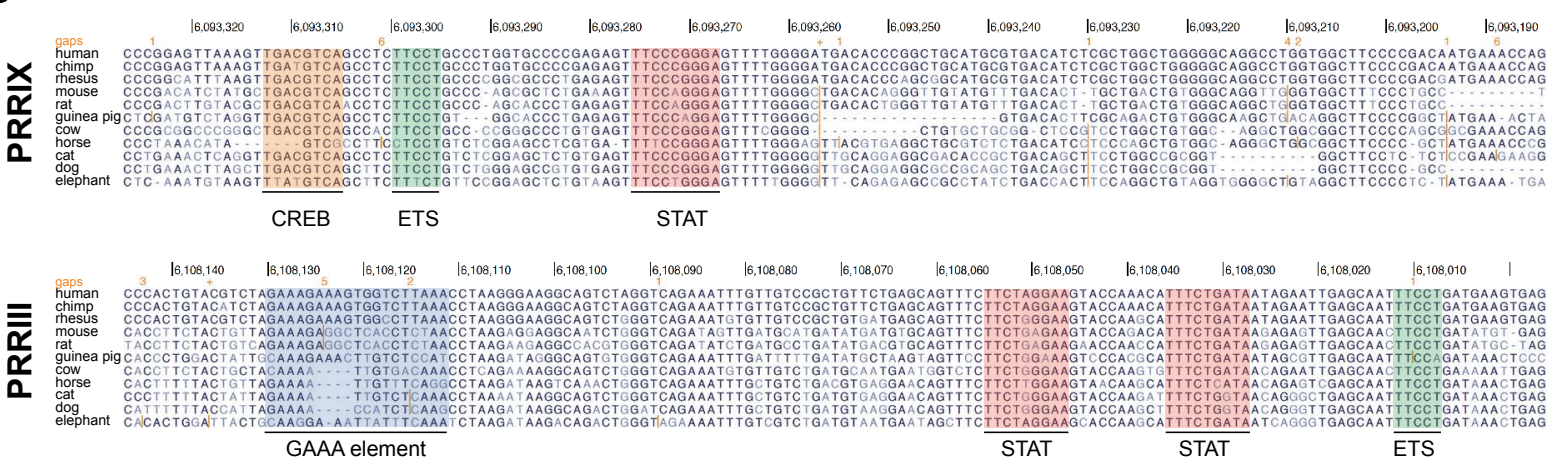

Figure 1: (A) UCSC genome browser screenshot of ENCODE DNase-seq in T-cell populations and CD20+ $\mathrm{B}$-cells at the IL2RA gene locus. Regulatory element annotation is provided underneath, as well as conserved motifs identified via phylogenetic footprinting (see Figure S1 for a full list). Red denotes open chromatin. (B) MultiZ alignments at PRRIX and PRRIII (top, bottom) in higher mammalian species. Conserved motifs are indicated in different colors. 
and S2B). The JAK-STAT responsive PRRIII also showed a high degree of conservation across mammals.

To determine the functionality of putative binding sites in PRRIX, we tested for the presence of specific protein complexes potentially binding this region in vitro via EMSA. To this end, employed nuclear extracts of $1 \mathrm{~h}$ IL-2-stimulated Kit 225 IL-2-dependent T-cell lymphoma cells [47] that had been starved of IL-2 for $20 \mathrm{hrs}$. We used a ${ }^{32} \mathrm{P}-$ labeled probe (B2) corresponding to a region of PRRIX harboring STAT, ETS and CREB motifs, using $1 \mathrm{~h} \mathrm{IL-2}$ induced nuclear protein extracts. We observed three specific protein complexes C1, C2 and C3 (Figures 2A and $2 \mathrm{~B}$ ) that disappeared using an unlabeled wild type version of the probe for region IX as a competitor in excess. The addition of a $25 \mathrm{x}$ excess of unlabeled, high-affinity competitors carrying the ETS and STAT motifs [33] did not alter complexes 1, 2 and 3, while the same excess of a high-affinity CREB competitor [42] caused the loss of complex 1 (Figures $2 \mathrm{~A}$ and $2 \mathrm{~B}$ ). We therefore conclude that a complex specifically binds the CREB motif isolated in PRRIX.

A protein complex containing Poly ADP-Ribose Polymerase 1 (PARP-1) binds a transcriptional repressor GAAA element in PRRIII

To determine whether the GAAA sequence identified in PRRIII corresponds to an open chromatin region, we first performed highresolution genomic in vivo footprinting using dimethyl sulfate/ligationmediated PCR (DMS/LMPCR, Figure 3A and Table 1). We detected a chromatin-modified element in both purified $\mathrm{CD}^{+} \mathrm{T}$ Cells (Figure 3B) and Kit 225 cells (Figure 3C) using $\alpha \mathrm{CD} 2 / \alpha \mathrm{CD} 28$ and IL-2 activation, respectively. In order to verify that nuclear protein complexes can bind the GAAA element, we then performed EMSA using a ${ }^{32}$ P-labeled probe containing the GAAA sequence $\left(\mathrm{GAAA}_{\mathrm{wt}}\right)$ on Kit 225 nuclear extracts. We detected three specific protein-DNA complexes referred to as $\mathrm{C} 1, \mathrm{C} 2$ (a compound of two closely migrating complexes, C2a and $\mathrm{C} 2 \mathrm{~b}$ ), and $\mathrm{C} 3$ that disappeared when competing against an unlabeled GAAA $_{w t}$ probe in excess (Figures $4 \mathrm{~A}$ and $4 \mathrm{~B}$ ). Competition experiments using an unlabeled probe bearing a mutant 3 ' end of the GAAA motif $\left(\mathrm{GAAA}_{\text {mul }}\right.$ ) resulted in the loss of $\mathrm{C} 2 \mathrm{a} / \mathrm{b}$ and $\mathrm{C} 3$ (Figures $4 \mathrm{~A}$ and $4 \mathrm{C}$ ). Conversely, the use of an unlabeled competitor probe with a disrupted GAAA repeat $\left(\mathrm{GAAA}_{\text {mut23 }}\right)$ resulted in the maintenance of $\mathrm{C} 2 \mathrm{a} / \mathrm{b}$. Further, using an unlabeled competitor disrupting both the GAAA repeat and the TGTT 3 ' end of the sequence, but recreating a single GAAA motif on the antisense strand $\left(\mathrm{GAAA}_{\text {mut123 }}\right.$ ) again resulted the loss of $\mathrm{C} 2 \mathrm{a} / \mathrm{b}$ and $\mathrm{C} 3$. Altogether, this implies that (i) the $\mathrm{C} 2 \mathrm{a} / \mathrm{b}$ protein complex specifically binds the GAAA element, (ii) that the 3' TGTT sequence is not required for binding of this complex and that (iii) a single GAAA repeat is sufficient for $\mathrm{C} 2 \mathrm{a} / \mathrm{b}$ binding.

We next wanted to determine whether the GAAA element is transcriptionally active. We performed gene reporter assays in Kit 225 cells stimulated or not by IL-2 [47]. We found that the insertion of GAAA $_{\mathrm{wt} \times 3}$ upstream of the $\mathrm{\kappa B}$ amplifier strongly decreases IL2RA gene expression regardless of IL-2 stimulation (Figure $4 \mathrm{D}$ ). This suggests that GAAA is a constitutive repressor of IL2RA expression in this context.

We then proceeded to identifying protein complexes that interact with GAAA. We carried out DNA Affinity Purification Assays (DAPA) using Kit 225 nuclear extracts and thus defined two specific components at 90 and $45 \mathrm{kDa}$ that reacted with the $\mathrm{GAAA}_{\mathrm{wt}}$ probe but not the control $\mathrm{GAAA}_{\mathrm{mu} 1}$ or GASd probes (Figure 4E). Interestingly, these complexes

A

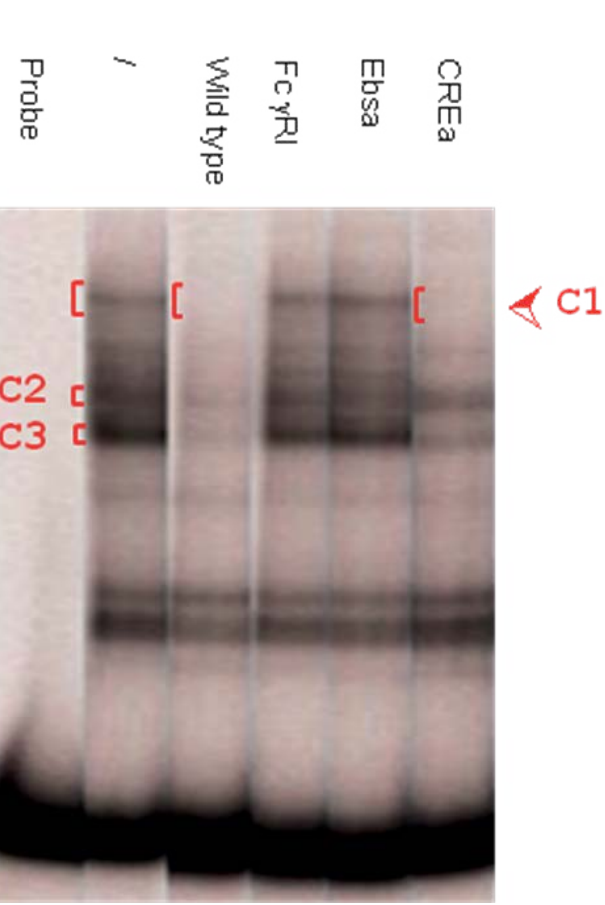

PRRIX $_{\text {wt }}$ probe (chr10:6,092,739-6,095,571): GAGTTAAAGTTGACGTCAGCCTCTTCCTGCCC TGGTGCCCCGAGAGTTTCCCGGGAGTTTTGG

\author{
FcgRI-GAS competitor: \\ GTATTTCCCAGAAAAGGAAC
}

EBSa competitor:

GATAAACAGGAAGTGGTTGTA

CREa competitor:

CGCCTTGAATGACGTCAAGGC

Figure 2: (A) Electrophoretic mobility shift assay (EMSA) assays performed using a ${ }^{32} \mathrm{P}$ labeled $\mathrm{IX}_{\mathrm{wt}}$ probe only (leftmost), labeled IX ${ }_{\mathrm{wt}}$ probe plus nuclear extracts (second leftmost) reveal three protein complex that disappear using the labeled IX $\mathrm{X}_{w t}$ probe plus the competing non labeled IX in excess (third leftmost). These complexes do not disappear when using the labeled IX $\mathrm{X}_{w t}$ probe plus labeled IX probe plus ETS1 Ebsa competitor probe in excess (second rightmost). However the labeled IX $X_{w t}$ probe plus CREa high-affinity competitor probe in excess causes the loss of complex C1 which binds to the CREB CREa competitor. (B) DNA sequences for the probes used in EMSA. Putative transcription factor binding sites are indicated in bold. 
Citation: Rosa F, Rameil P, Algarte-Genin M, Bedotto M, Ferrier P, et al. (2018) Identification of Two Novel Regulatory Elements in the IL2RA Gene Locus. J Pulm Respir Med 8: 458. doi: 10.4172/2161-105X.1000458

A

-4050 TTCTGCCCTTAGCTTCTACCCCTCTCTACTTCT AAGACGGGAATCGAAGATGGGGAGAGATGAAGA

GGTTAACTATGGACCACACTCTGCTTCCTCAGGAACCACCTACCAAGGCCGTATCCATCCTTCAAGGACA CCAATTGATACCTGGTGTGAGACGAAGGAGTCCTTGGTGGATGGTTCCGGCATAGGTAGGAAGTTCCTGT

ATACGTGGGCCTTTCCTGATCACATCAGCTCAACAACTTTTCCCTCCTACATTTCAATTGCTCTTCTTAC TATGCACCCGGAAAGGACTAGTGTAGTCGAGTTGTTGAAAAGGGAGGATGTAAAGTTAACGAGAAGAATG

GAA

CATAATCATTAGTATTCACCCCACTGTACGTCTAGAAAGAAAGTGGTCTTAAACCTAAGGGAAGGCAGTC GTATTAGTAATCATAAGTGGGGTGACATGCAGATCTTTCTTTCACCAGAATTTGGATTCCCTTCCGTCAG

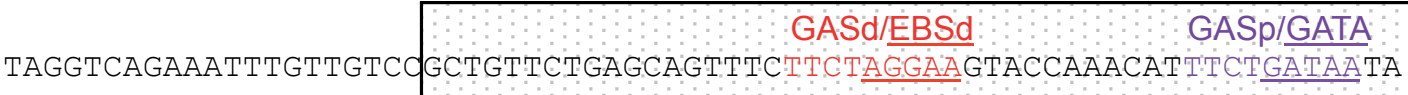
ATCCAGTCTTTAAACAACAGGCGACAAGACTCGTCAAAGAAGATCCTTCATGGTTTGTAAAGACTATTAT EBSp

GAATTAGCAATTTCCTATGAGTGAGACTCAGCTTGCACTGTTGACCGGCTGTCCTGGATGAACCTAG CTTAACTCGTTAAAGGACTACTTCACTCTGAGTCGAACGTGACAACTGGCCGACAGGACCTACTTGGATC

TTACTTTTAАCСAААTGTCCTTTCTTGAACTTGTTCCTTTCTTGAACTTAATCTATC $\quad-3610$ AATGAAAATTGGTTTACAAGGAAAGAACTTGAACAAGGAAAGAACTTGAATTAGATAG

B

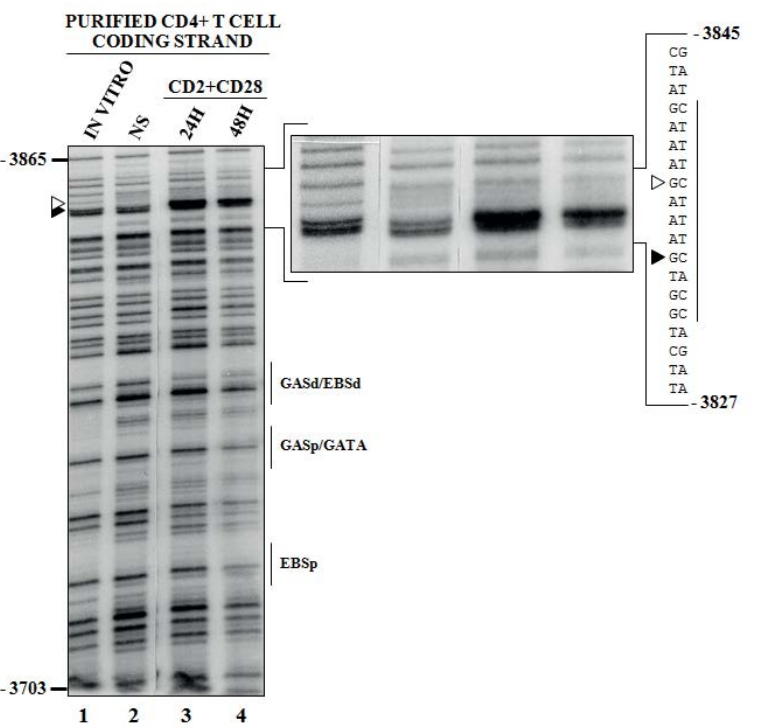

C

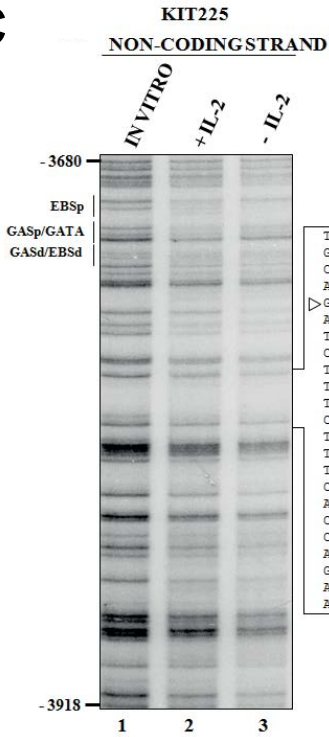

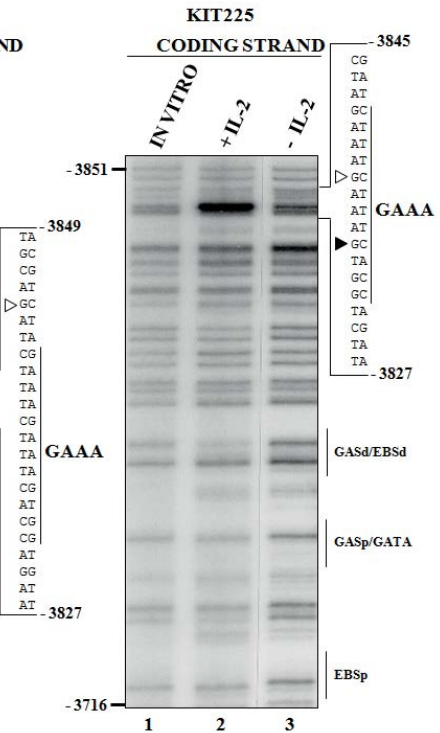

Figure 3: (A) Partial nucleotide sequence of the 5' non-coding region [-4050,-3610] of the human IL2RA gene. The position and nature of different transcription factor binding are highlighted above the sequence. The PRRIII region $[-3786,-3701]$ is highlighted in a grayed-out box. The sequence position of primer sets is represented by colored arrows.

(B) In vivo genomic footprinting detection assays via a DMS/LMPCR method carried out on the coding strand of PRRIII in human IL2RA, using genomic DNA from PBMC purified primary human CD4 ${ }^{+} \mathrm{T}$ Cells, using primers 4,5,6 (Table 1): naked DNA (lane 1), resting T Cell DNA (lane 2), $24 \mathrm{~h}$ (lane 3 ) and $48 \mathrm{~h}$ aCD2+ $\mathrm{aCD} 28$ stimulation. Magnification of the region containing GAAA shows precise nucleotide position (left), where sites are listed. Empty arrows indicate constitutive and inducible occupancy, respectively.

(C) In vivo genomic footprinting detection assays via a DMS/LMPCR method carried out on region PRRIII of human IL2RA, using genomic DNA from human leukemic Kit $225 \mathrm{~T}$ cells on the coding strand (left) or the non-coding strand (right), using primers 1,2 and 3 (left) or 4,5 and 6 (right): naked DNA (lane 1), $24 \mathrm{~h}$ IL-2 stimulated (lane 2) or 48 h IL-2 deprived (lane 3) Kit 225 cells. Precise sites are shown. Empty arrows indicate constitutive and inducible occupancy, respectively.

were obtained regardless of IL-2 activation. We subsequently extracted, purified these bands and performed mass-spectrometry sequencing for identification of bound protein complexes. While we could not identify the complex at $45 \mathrm{kDa}$, the complex migrating at $90 \mathrm{kDa}$ was identified as Poly ADP-Ribose Polymerase 1 (PARP-1). Consistent with its constitutive repressive activity, this suggests that GAAA is also bound in a constitutive manner by at least PARP-1.

\section{Discussion}

In this work, we have expanded the comprehensive repertoire of regulatory elements governing CD25 expression. PRRIX was already described as a JAK-STAT responsive element with a functional STAT5 binding site [40]. The addition of a CREB site further makes it CD28responsive. This suggests a dual role for this enhancer, likely responsive 
A

\section{GAAAwt}

CTAGAAAGAAAGTGGTCTTAA

GATCTTTCTTTCACCAGAATT

GAAAMU 1

CTAGAAAGAAATGTTTCTTAA

GATCTTTCTTTACAAAGAATT

GAAAMU23

CTACCAACCAAGTGGTCTTAA

GATGGTTCCTTCACCAGAATT

GAAAmu 123

CTACCAACCAATGTTTCTTAA

GATGGTTCCTTACAAAGAATT
B

C
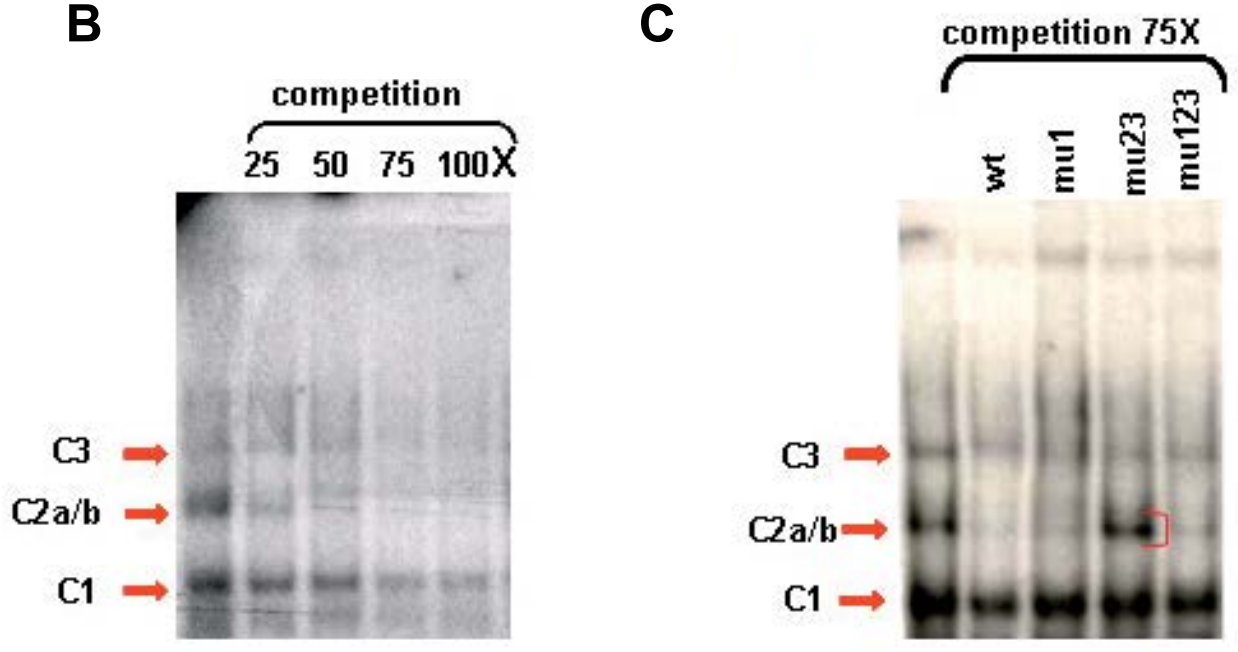

D

$\mathbf{E}$
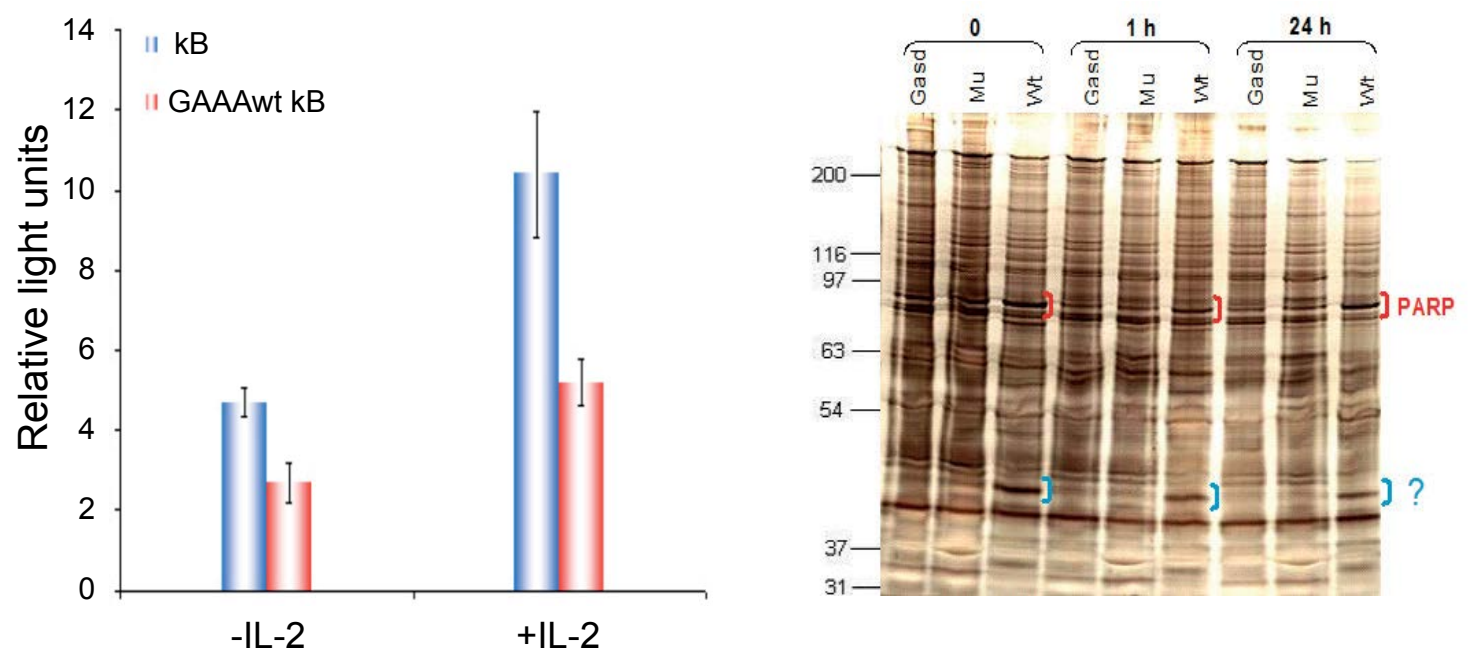

Figure 4: (A) Probe sequences of used in EMSAs around the GAAA element.

(B) EMSAs using the labeled GAAA $\mathrm{wt}_{\mathrm{t}}$ probe with nuclear extracts only (leftmost) which reveals three protein complexes (C2a/b and C3) that disappear when using 75X non labeled GAAA probe competition (second rightmost).

(C) EMSAs using the labeled GAAA with no competitor (leftmost), with 25X unlabeled competitor excess of GAAAwt (second leftmost), GAAA (third leftmost) and GAAA ${ }_{\text {mu123 }}$ (rightmost) which do not affect binding since complexes $\mathrm{C} 2 \mathrm{a} / \mathrm{b}$ and $\mathrm{C} 3$ are lost, and GAAA ${ }_{\text {mu23 }}$ (second rightmost) which affects binding of C2a/b and C3 since they are not lost.

(D) Transcriptional effect of a GAAA trimer on the luciferase reporter gene without (left) and with (right) $1 \mathrm{~h}$ IL-2 stimulation in Kit 225 cells shows the in vivo

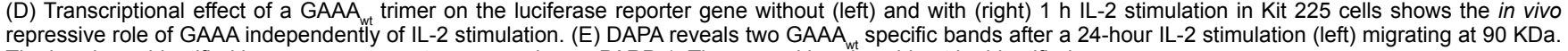
The band was identified in mass spectrometry sequencing as PARP-1. The second band could not be identified.

to both low- and high-affinity IL-2 receptors. It would thus be activated during initial antigen presentation whereby CD25 expression is still low, and would play a further role in the amplification of IL2RA expression via JAK-STAT signaling. The addition of a CD28-responsive element to the regulation of IL2RA further highlights the importance of this locus in $\mathrm{T}_{\text {reg }}$ ontogeny. In addition, we observed that PRRVI was not well conserved among mammals, hinting at the need for an ancestral CD28-responsive element. This enhancer might very well be PRRIX, harboring both well conserved JAK-STAT and CD28 responsive elements. Other less conserved enhancers may thus have arisen later in evolution as more specialized elements. Interestingly, we observed that PRRIX was constitutively accessible in all T-cell populations, as well as in B-cells (Figure 1A). Along with its high degree of conservation, this might indicate that this enhancer is used in other cell types expressing CD25 and ancestral. Importantly, we also provide a detailed description of novel, putative transcription factor binding sites that can be directly 
used as a base for the identification of further regulatory elements in the IL2RA gene locus (Figures S1 and S2).

We further identified a repressor element as the GAAA sequence near the 5' end of PRRIII. The importance of this identification leans more particularly on the fact that so far only negative regulatory elements, NRE-1 and NRE-2, have been identified in the IL2RA locus [48]. The GAAA element might thus regulate the trans-activity of PRRIII and negatively influence the feed-forward mechanism conferred by PRRIII and IV via JAK-STAT signaling. Thus, GAAA may act as a brake on top of NRE-1/2 and SOCS proteins on CD25 amplification. Interestingly, we also identified PARP-1 as part of the complex that binds GAAA. Albeit originally identified as a single and double strand DNA break sensor and repair protein, PARP-1 was shown to play an important role in transcription [49]. PARP-1 was also shown to promote apoptosis, consistent with the repression of CD25 and its activated cell survival and activated genes [50]. PARP-1 contains a central proteinprotein interaction domain and an amino-terminal domain capable of interaction with DNA through two zinc fingers and a helix-turn-helix motif. PARP-1 was also described as a transcriptional repressor that acts downstream of CD28 signaling [51], which may indicate a repressor activity promoted by CD28-dependent recruitment of PARP-1 to this region. This finding would add PRRIII to the list of CD28-responsive elements. However, PRRIII is not a constitutively open enhancer, as attested by DNaseI-seq profilings shown in Figure 1A. Its accessibility is however maintained in $\mathrm{Th}_{1}, \mathrm{Th}_{17}$ and $\mathrm{T}_{\text {regs }}$, similarly to our previous observation that the presence of stable preassembled protein-DNA complexes, in contrast with the bare IL2RA locus in non-T cells, contributes precommitment of $\mathrm{T}$ cells to activation [52]. Interestingly, PARP-1 was also shown to facilitate chromatin remodeling at pioneered enhancers independently of its poly(ADP-ribosyl) transferase activity [53], hinting at a possible dual role for PARP-1 in this context. This enhancer may thus play a role in the acquisition of epigenetic memory and primed for immediate CD25 expression upon re-stimulation in $\mathrm{Th}_{1} / \mathrm{Th}_{17}$ cells [54]. Further, as we observed protein complexes binding to GAAA in both the absence and presence of IL-2, this suggests that this element is a constitutive repressor. The lack of interaction with the GASd probe also effectively rules out STAT5 as binding to GAAA. The molecular weight $(45 \mathrm{kDa})$ of the unidentified protein that was pulled down via DAPA also seems to prohibit the presence of STAT proteins. Other possible candidates could be IRF1 and IRF2 [55-59], which both migrate at $45 \mathrm{KDa}$ and whose binding motif is GAAA. While IRF1 was largely described as a transcriptional activator and IRF2 as a transcriptional repressor [60], IRF1 was however shown to downregulate $\mathrm{CD} 4{ }^{+} \mathrm{CD} 25^{+}$regulatory T-Cell differentiation through FoxP3 down-regulation [61]. Thus additional repression of IL2RA could be used in this case, as well as suppressing $\mathrm{Th}_{2}$ differentiation while promoting that of $\mathrm{Th}_{1}$ upon activation through interferon $\gamma(\mathrm{IFN} \gamma)$ production [62].

Recent studies have also established that the main role of the IL-2/ IL-2R system consists in controlling lymphocyte homeostasis [63]. Dysfunctions of this system can prove devastating since regulatory T-Cells normally temper humoral and cell-mediated immune responses [64]; and also normally suppress autoreactive T-cells that have escaped negative selection [65]. At least two reports have also shown that abnormal T-Cell suppression by regulatory T-Cells can lead to evasive mechanisms that may profit to cancer development $[66,67]$. This alone justifies anti CD25 monoclonal treatment in these pathologies. On the other hand, loss of $\mathrm{T}_{\text {reg }}$ populations leading to increased allergic and autoimmune reactions [10-13], one natural approach would entail treating such patients with IL-2. Importantly, the recent finding that low-dose IL-2 administration tends to suppress autoimmune disease and inflammation supports the requirement for fine-tuning of IL2RA transcriptional regulation [68]. Overall, we present two novel CD2$\mathrm{CD} 28$ responsive regulatory features of the human $I L 2 R A$ gene that are part of fine-tuned, time-dependent regulatory mechanisms that govern the expression of this gene and control $\mathrm{T}_{\mathrm{reg}}$ ontogeny.

\section{Acknowledgments}

FR was a Ligue Nationale Contre le Cancer (LNCC) fellow, PC was an Institut National du Cancer (INCa) and Fondation pour la Recherche Medicale (FRM) fellow. Work in the Imbert's lab is supported by INCa, LNCC, Association pour la Recherche contre le Cancer (ARC), Agence Nationale pour la Recherche (ANR) and GIS IBiSA (Infrastructures en Biologie Santé et Agronomie). Work in the Ferrier laboratory is supported by institutional grants from Inserm and CNRS, and by specific grants from the Commission of the European Communities, the ANR, INCa, ARC, the "Fondation de France/Comité Leucémie", the "Fondation Princesse Grace de Monaco", and the "Fondation Laurette Fugain". We express our special thanks to Touati Benoukraf for his invaluable advice.

\section{References}

1. Sakaguchi S, Sakaguchi N, Asano M, Itoh M, Toda M (1995) Immunologic selftolerance maintained by activated $\mathrm{T}$ cells expressing IL-2 receptor alpha-chains (CD25). Breakdown of a single mechanism of self-tolerance causes various autoimmune diseases. J Immunol 155: 1151-1164.

2. Hori S, Nomura T, Sakaguchi S (2003) Control of regulatory T cell development by the transcription factor Foxp3. Science 299: 1057-1061.

3. Zhu J, Yamane H, Paul WE (2010) Differentiation of effector CD4 T cell populations (*). Annu Rev Immunol 28: 445-489.

4. Read S, Malmström V, Powrie F (2000) Cytotoxic T lymphocyte-associated antigen 4 plays an essential role in the function of CD25(+)CD4(+) regulatory cells that control intestinal inflammation. J Exp Med 192: 295-302.

5. Annacker O, Asseman C, Read S, Powrie F (2003) Interleukin-10 in the regulation of T cell-induced colitis. J Autoimmun 20: 277-279.

6. Rivas MN, Chatila TA (2016) Regulatory T cells in allergic diseases. J Allergy Clin Immunol 138: 639-652.

7. Larche M (2007) Regulatory T cells in allergy and asthma. Chest 132:10071014.

8. Taylor A, Verhagen J, Akdis CA, Akdis M (2004) T regulatory cells in allergy and health: A question of allergen specificity and balance. Int Arch Allergy Immunol 135: 73-82.

9. Akdis CA, Akdis M (2014) Mechanisms of immune tolerance to allergens: Role of IL-10 and Tregs. J Clin Invest 124: 4678-4680.

10. Shi YH, Shi GC, Wan HY, Ai XY, Zhu HX, et al. (2013) An increased ratio of Th2/Treg cells in patients with moderate to severe asthma. Chin Med J (Engl) 126: $2248-2253$

11. Shi YH, Shi GC, Wan HY, Jiang LH, Ai XY, et al. (2011) Coexistence of Th1/Th2 and Th17/Treg imbalances in patients with allergic asthma. Chin Med J (Engl) 124: $1951-1956$

12. Talaat RM, Mohamed SF, Bassyouni IH, Raouf AA (2015) Th1/Th2/Th17/ Treg cytokine imbalance in systemic lupus erythematosus (SLE) patients: Correlation with disease activity. Cytokine 72: 146-153.

13. Smith M, Tourigny MR, Noakes P, Thornton CA, Tulic MK, et al. (2008) Children with egg allergy have evidence of reduced neonatal CD4(+)CD25(+) CD127(lo/-) regulatory T cell function. J Allergy Clin Immunol 121: 1460-1466.

14. Kim HP, Imbert J, Leonard WJ (2006) Both integrated and differential regulation of components of the IL-2/IL-2 receptor system. Cytokine Growth Factor Rev 17: 349-66.

15. Liao W, Lin JX, Leonard WJ (2011) IL-2 family cytokines: New insights into the complex roles of IL-2 as a broad regulator of $\mathrm{T}$ helper cell differentiation. Curr Opin Immunol 23: 598-604.

16. Umlauf SW, Beverly B, Lantz O, Schwartz RH (1995) Regulation of interleukin 2 gene expression by CD28 costimulation in mouse T-cell clones: Both nuclear and cytoplasmic RNAs are regulated with complex kinetics. Mol Cell Biol 15: 3197-3205. 
17. Shortman K, Wu L (1996) Early T lymphocyte progenitors. Annu Rev Immuno 14: $29-47$.

18. Stockinger $H$, Valent $P$, Majdic O, Bettelheim P, Knapp W (1990) Human blood basophils synthesize interleukin-2 binding sites. Blood 75: 1820-1826.

19. Waldmann TA (1989) The multi-subunit interleukin-2 receptor. Annu Rev Biochem 58: 875-911.

20. Deneys V, Mazzon AM, Marques JL, Benoit H, De Bruyère M (2001) Reference values for peripheral blood B-lymphocyte subpopulations: A basis for multiparametric immunophenotyping of abnormal lymphocytes. J Immunol Methods 253: 23-36.

21. Darnell JE Jr, Kerr IM, Stark GR (1994) Jak-STAT pathways and transcriptional activation in response to IFNs and other extracellular signaling proteins. Science 264: 1415-1421.

22. Nakamura KD, Martinez R, Weber MJ (1983) Tyrosine phosphorylation of specific proteins after mitogen stimulation of chicken embryo fibroblasts. Mol Cell Biol 3: 380-390.

23. Whitman M, Downes CP, Keeler M, Keller T, Cantley L (1988) Type I phosphatidylinositol kinase makes a novel inositol phospholipid, phosphatidylinositol-3-phosphate. Nature 332: 644-646.

24. Martin R (2012) Anti-CD25 (daclizumab) monoclonal antibody therapy in relapsing-remitting multiple sclerosis. Clin Immunol 142: 9-14.

25. Schorle H, Holtschke T, Hünig T, Schimpl A, Horak I (1991) Development and function of $\mathrm{T}$ cells in mice rendered interleukin-2 deficient by gene targeting Nature 352: 621-624.

26. Kim HP, Kim BG, Letterio J, Leonard WJ (2005) Smad-dependent cooperative regulation of interleukin 2 receptor alpha chain gene expression by $\mathrm{T}$ cell receptor and transforming growth factor-beta. J Biol Chem 280: 34042-34047.

27. Schade RP, Van leperen-Van Dijk AG, Versluis C, Van Reijsen FC, Kimpen JL, et al. (2002) Cell-surface expression of CD25, CD26, and CD30 by allergenspecific $\mathrm{T}$ cells is intrinsically different in cow's milk allergy. J Allergy Clin Immunol 109: 357-362.

28. Cross SL, Halden NF, Lenardo MJ, Leonard WJ (1989) Functionally distinct NF-kappa B binding sites in the immunoglobulin kappa and IL-2 receptor alpha chain genes. Science 244: 466-469.

29. John S, Reeves RB, Lin JX, Child R, Leiden JM, et al. (1995) Regulation of cell-type-specific interleukin-2 receptor alpha-chain gene expression: Potential role of physical interactions between Elf-1, HMG-I(Y) and NF-kappa B family proteins. Mol Cell Biol 15: 1786-1796.

30. Yeh JH, Lecine P, Nunes JA, Spicuglia S, Ferrier P, et al. (2001) Novel CD28responsive enhancer activated by $C R E B / A T F$ and AP-1 families in the human interleukin-2 receptor alpha-chain locus. Mol Cell Biol 21: 4515-4527.

31. John S, Robbins CM, Leonard WJ (1996) An IL-2 response element in the human IL-2 receptor alpha chain promoter is a composite element that binds Stat5, Elf-1, HMG-I(Y) and a GATA family protein. EMBO J 15: 5627-5635.

32. Lecine P, Algarte M, Rameil P, Beadling C, Bucher P, et al. (1997) Elf-1 and Stat5 bind to a critical element in a new enhancer of the human interleukin-2 receptor alpha gene. Mol Cell Biol 17: 2351.

33. Rameil P, Lecine P, Ghysdael J, Gouilleux F, Kahn-Perles B, et al. (2000) IL-2 and long-term $T$ cell activation induce physical and functional interaction between STAT5 and ETS transcription factors in human T cells.Oncogene 19 : 2086-2097.

34. Kim HP, Leonard WJ (2002) The basis for TCR-mediated regulation of the IL-2 receptor alpha chain gene: Role of widely separated regulatory elements. EMBO J 21: 3051-3059.

35. Bucher P, Corthésy P, Imbert J, Nabholz M (1997) A conserved IL-2 responsive enhancer in the IL-2R alpha gene. Immunobiol 198: 136-43.

36. Tagle DA, Koop BF, Goodman M, Slightom JL, Hess DL, et al. (1988) Embryonic epsilon and gamma globin genes of a prosimian primate (Galago crassicaudatus). Nucleotide and amino acid sequences, developmental regulation and phylogenetic footprints. J Mol Biol 203: 439-455.

37. Schmidl C, Klug M, Boeld TJ, Andreesen R, Hoffmann P, et al. (2009) Lineagespecific DNA methylation in T cells correlates with histone methylation and enhancer activity. Genome Res 19: 1165-1174

38. Simeonov DR, Gowen BG, Boontanrart M, Roth TL, Gagnon JD, et al.
(2017) Discovery of stimulation-responsive immune enhancers with CRISPR activation. Nature 549: 111-115.

39. Neph S, Vierstra J, Stergachis AB, Reynolds AP, Haugen E, et al. (2012) An expansive human regulatory lexicon encoded in transcription factor footprints. Nature 489: 83-90.

40. Li P, Mitra S, Spolski R, Oh J, Liao W, et al. (2017) STAT5-mediated chromatin interactions in superenhancers activate IL-2 highly inducible genes: Functional dissection of the II2ra gene locus. Proc Natl Acad Sci USA 114: 12111-12119.

41. Lecine P, Algart e M, Rameil P, Beadling C, Bucher P, et al. (1996) Elf-1 and Stat5 bind to a critical element in a new enhancer of the human interleukin-2 receptor alpha gene. Mol Cell Biol 16: 6829-6840.

42. Plet A, Huet X, Algarte M, Rech J, Imbert J, et al. (1997) Relief of cyclin A gene transcriptional inhibition during activation of human primary $T$ lymphocytes via CD2 and CD28 adhesion molecules. Oncogene 14: 2575-2583.

43. Kadonaga JT, Tjian R(1986) Affinity purification of sequence-specific DNA binding proteins. Proc Natl Acad Sci USA 83: 5889-5893.

44. Ovcharenko I, Nobrega MA, Loots GG, Stubbs L (2004) ECR browser: A too for visualizing and accessing data from comparisons of multiple vertebrate genomes. Nucleic Acids Res 32: W280-286.

45. Karolchik D, Hinrichs AS, Kent WJ (2007) The UCSC Genome Browser. Curr Protoc Bioinformatics 1: 1.4 .

46. Thompson JD, Higgins DG, Gibson TJ (1994) CLUSTAL W: Improving the sensitivity of progressive multiple sequence alignment through sequence weighting, position-specific gap penalties and weight matrix choice. Nucleic Acids Res 22: 4673-4680.

47. Hori T, Uchiyama T, Tsudo M, Umadome H, Ohno H, et al. (1987) Establishmen of an interleukin 2-dependent human $\mathrm{T}$ cell line from a patient with $\mathrm{T}$ cell chronic lymphocytic leukemia who is not infected with human T cell leukemia/lymphoma virus. Blood 70: 1069-1072.

48. Smith MR, Greene WC (1989) The same 50-kDa cellular protein binds to the negative regulatory elements of the interleukin 2 receptor alpha-chain gene and the human immunodeficiency virus type 1 long terminal repeat. Proc Natl Acad Sci USA 86: 8526-8530.

49. Kraus WL, Lis JT (2003) PARP goes transcription. Cell 113: 677-683.

50. Chiarugi A, Moskowitz MA (2002) Cell biology. PARP-1--a perpetrator of apoptotic cell death?. Science 297: 200-201.

51. Collette Y, Benziane A, Razanajaona D, Olive D, et al. (1998) Distinct regulation of T-cell death by CD28 depending on both its aggregation and T-cell receptor triggering: A role for Fas-FasL. Blood 92: 1350-1363.

52. Algarte M, Lecine $P$, Costello $R$, Plet A, Olive D, Imbert J (1995) In vivo regulation of interleukin-2 receptor alpha gene transcription by the coordinated binding of constitutive and inducible factors in human primary T cells. EMBO J 14: 5060-5072

53. Liu Z, Kraus WL (2017) Catalytic-Independent Functions of PARP-1 Determine Sox2 Pioneer Activity at Intractable Genomic Loci. Mol Cell 65: 589-603 e9.

54. Bevington SL, Cauchy P, Piper J, Bertrand E, Lalli N, et al. (2016) Inducible chromatin priming is associated with the establishment of immunological memory in T cells. EMBO J 35: 515-535.

55. T Fujita, L F Reis, N Watanabe, Y Kimura, T Taniguchi, et al. (1989) Induction of the transcription factor IRF-1 and interferon-beta mRNAs by cytokines and activators of second-messenger pathways. Proc Natl Acad Sci U S A 86: 9936-9940.

56. Harada H1, Fujita T, Miyamoto M, Kimura Y, Maruyama M, et al. (1989) Structurally similar but functionally distinct factors, IRF-1 and IRF-2, bind to the same regulatory elements of IFN and IFN-inducible genes. Cell 58: 729-739.

57. T Fujita, L F Reis, N Watanabe, Y Kimura, T Taniguchi, et al. (1989) Induction of endogenous IFN-alpha and IFN-beta genes by a regulatory transcription factor, IRF-1. Nature 337: 270-272.

58. Fujita T1, Sakakibara J, Sudo Y, Miyamoto M, Kimura Y, et al. (1988) Evidence for a nuclear factor(s), IRF-1, mediating induction and silencing properties to human IFN-beta gene regulatory elements. EMBO J 7: 3397-3405.

59. Miyamoto M1, Fujita T, Kimura Y, Maruyama M, Harada $H$, et al. (1988) Regulated expression of a gene encoding a nuclear factor, IRF-1, that specifically binds to IFN-beta gene regulatory elements. Cell 54: 903-913. 
Citation: Rosa F, Rameil P, Algarte-Genin M, Bedotto M, Ferrier P, et al. (2018) Identification of Two Novel Regulatory Elements in the IL2RA Gene Locus. J Pulm Respir Med 8: 458. doi: 10.4172/2161-105X.1000458

60. Tjian R, Maniatis T (1994) Transcriptional activation: A complex puzzle with few easy pieces. Cell $77: 5-8$

61. Fragale A, Gabriele L, Stellacci E, Borghi P, Perrotti E, et al. (2008) IFN regulatory factor- 1 negatively regulates $\mathrm{CD} 4+\mathrm{CD} 25+$ regulatory $\mathrm{T}$ cell differentiation by repressing Foxp3 expression. J Immunol 181: 1673-1682.

62. Scott $P$ (1991) IFN-gamma modulates the early development of Th1 and Th2 responses in a murine model of cutaneous leishmaniasis. J Immunol 147: 3149-3155.

63. Malek TR, Bayer AL (2004) Tolerance, not immunity, crucially depends on IL-2. Nat Rev Immunol 4: 665-674.

64. Sakaguchi S (2004) Naturally arising CD4+ regulatory t cells for immunologic self-tolerance and negative control of immune responses. Annu Rev Immunol 22: $531-562$.

65. Sakaguchi S (2000) Regulatory T cells: Key controllers of immunologic selftolerance. Cell 101: 455-458.

66. Vojdani A, Erde J (2006) Regulatory T Cells, a potent immunoregulatory target for cam researchers: Modulating tumor immunity, autoimmunity and alloreactive immunity (III). Evid Based Complement Alternat Med 3: 309-316.

67. Terabe M,Berzofsky JA (2004) Immunoregulatory T cells in tumor immunity. Curr Opin Immunol 16: 157-162.

68. Klatzmann D, Abbas AK (2015) The promise of low-dose interleukin-2 therapy for autoimmune and inflammatory diseases. Nat Rev Immunol 15: 283-294. 